Iranian Journal of Breast

Diseases. 2021; 13(4):33-39.
Original Article

\section{Compare of Sensitivity and Specificity of Liquid- Based and Conventional Cytology Smears in Fine Needle Aspirates for Diagnosis of Breast Mass}

\author{
Jafar Aghaei $\mathbf{M}^{1}$, Sajjadi $\mathbf{H}^{\mathbf{1}^{*}}$, Dehghani Zahedani $\mathbf{M}^{\mathbf{1}}$, Banihashemi $\mathbf{H}^{\mathbf{2}}$, \\ Booshehri $\mathbf{E}^{3}$ \\ ${ }^{1}$ Department of Pathology, Faculty of Medicine, Hormozgan University of \\ Medical Sciences, Bandar Abbas, Iran \\ 2 Department of Surgery, Faculty of Medicine, Hormozgan University of \\ Medical Sciences, Bandar Abbas, Iran \\ 3 Department of Public Health, Health School, Hormozgan University of \\ Medical Science, Bandar Abbas, Iran
}

Receive: 21/9/2020 Accepted: $30 / 11 / 2020$

"Corresponding Author: sajjadipathologyh@gmail.com

Ethics Approval: IR.HUMS.REC.1399.162

\begin{abstract}
Introduction: This study aimed to compare the cytology results obtained by the conventional smear method with those obtained by the liquid-based method for the diagnosis of palpable breast masses in women referred to the clinic of Shahid Mohammadi Hospital in Bandar Abbas city.
\end{abstract}

Methods: The research method was descriptive-cross-sectional. The research sample was selected based on purposive and availability sampling. Accordingly, 67 patients referred to the surgical clinic of Shahid Mohammadi Hospital in 2019-2020 were evaluated. The diagnostic sensitivity, diagnostic specificity, positive predictive value, and negative predictive value of conventional smear method and liquidbased method were compared.

Results: The diagnostic sensitivity of the conventional smear method was $88.4 \%$, specificity $94.9 \%$, positive predictive value $92 \%$, and negative predictive value $92.5 \%$. The diagnostic sensitivity of the liquid-based method was $84 \%$, specificity $90 \%$, positive predictive value $80.7 \%$, and negative predictive value $90 \%$.

Conclusion: Liquid-based method is better than conventional smear because of the ease of processing, faster screening, and preservation of cells and nuclear details. And it can be a promising and reliable method to diagnose palpable breast masses before surgery.

Keywors: Fine- Needle Aspiraton, ConventionalSmear Method, Liquid- Based Cytology Method, Breast Mass 


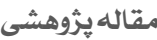

مقايسه حساسيت و ويزگى نمونهبر دارى سوزنى بين دو روش اسمير مرسوم و روش سيتولوزى مبتنى بر مايع در تودههاى قابل لمس دئ

עיזتان

معصومه جعفراقايى'، سيده حكيمه سجادى'"، محسن دهقانى زاهدانى'، سيد حسامالدين

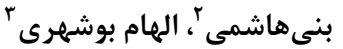

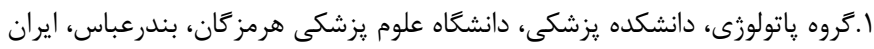

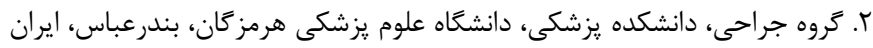

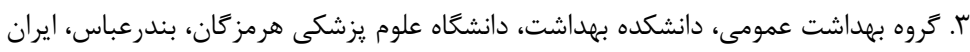

فصلنامه بيمارى هاى بستان ايران

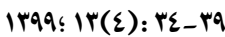

جكيده

مقدمه: هدف از مطالعه حاضر، مقايسه حساسيت و ويزَّى نتايج سيتولوزى در روش نمونهبردارى

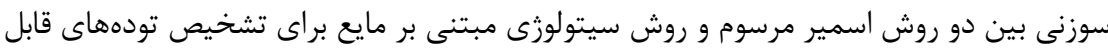

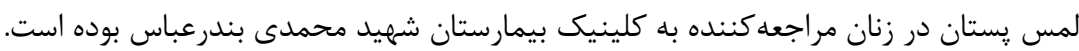
روش بررسى: روش يزوهش، توصيفى- مقطعى بود. نمونه يزوهش بر اساس نمونه كيرى هدفمند

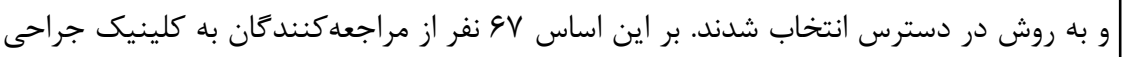

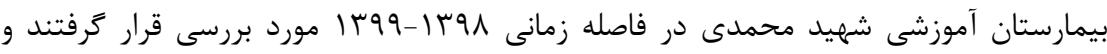

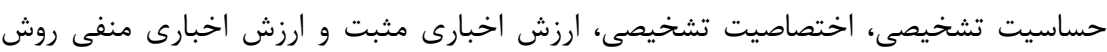
اسمير مرسوم و روش سيتولوزى مبتنى بر مايع با هم مقايسه شدند. اخداصن يافتهها: يافتهاى اين يزوهشى نشان داد، ميزان حساسيت تشخيصى روش مرسوم اسمير برابر

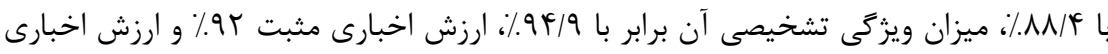
منفى 9r/a/ بوده است.

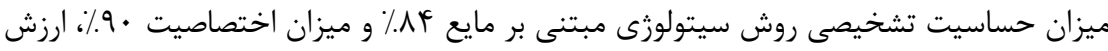

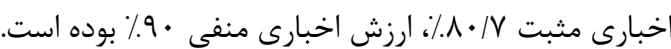
نتيجهَّيرى: نتايج يزوهش نشان داد روش سيتولورى مبتنى بر مايع به دليل تكنيك يردازش

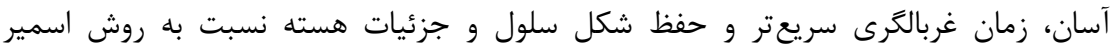

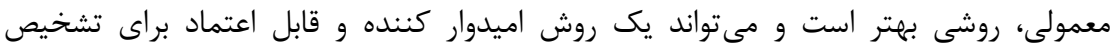

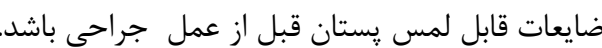
وازههاى كليدى: نمونهبردارى سوزنى، روش اسمير مرسوم، روش سيتولورى مبتنى بر مايع،

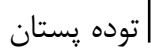

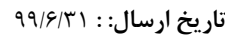

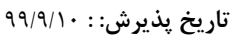

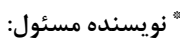
sajjadipathologyh@gmail.com 
يكنواخت است به همين دليل نمونه با سلولاريتى بالا و

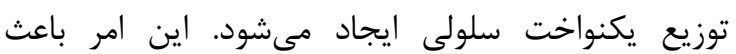

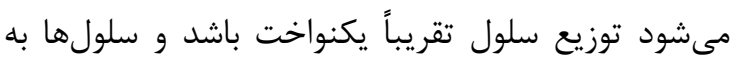

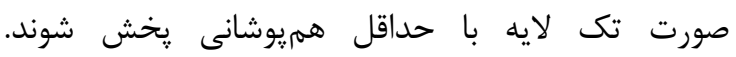
مورفولوزى سلولها به خوبى حفظ و تقويت شده و شكل حلى

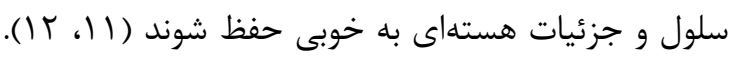

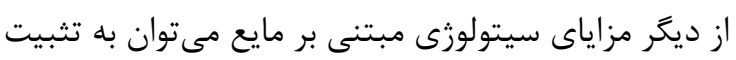

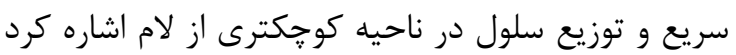

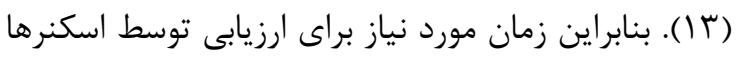

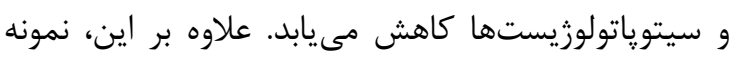

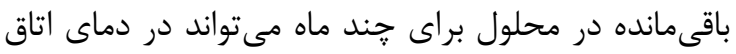

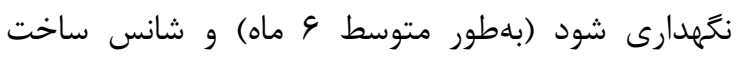
اسلايدهاى اضافى، يا بلوى سلولى، ايمونوسيتوشيمى، منوس،

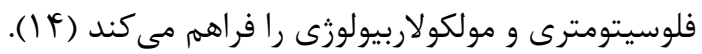

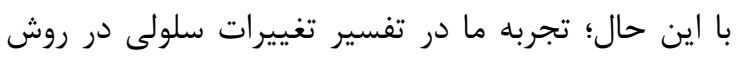

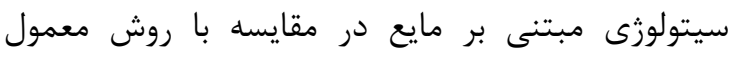

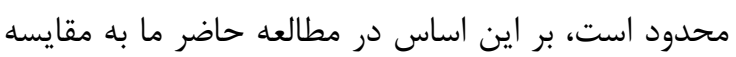

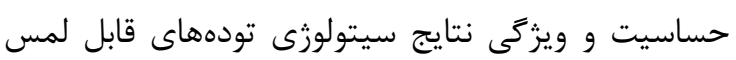

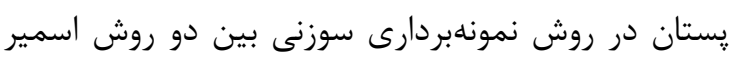

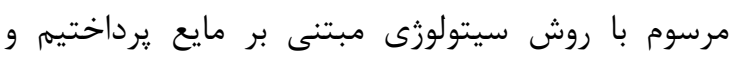

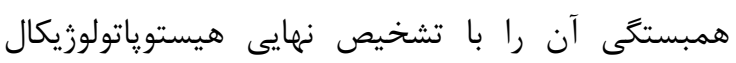

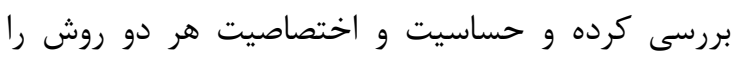
بر برسى كرديم. - (بر.

\section{مواد و روشها}

روش يزوهش توصيفى- مقطعى بود. با توجه به مطالعات

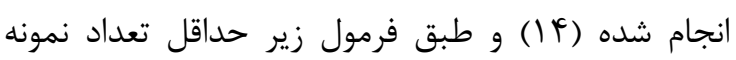

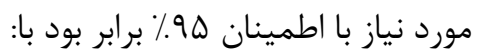

$\frac{Z^{2} p(1-P)}{d^{2}}=\frac{1.96^{2} \times 0.8 \times 0.2}{(0.1)^{2}}=61.44 \sim 62$ بلهبارت ديگر بو بيمار با توجه به معيارهاى ورود، به

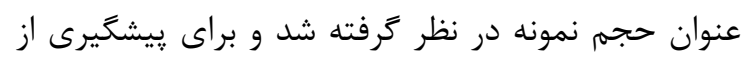

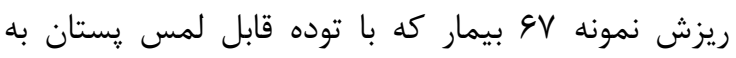

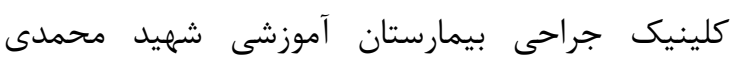

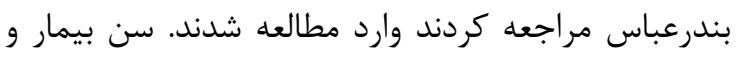

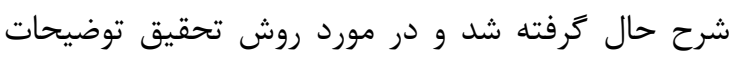

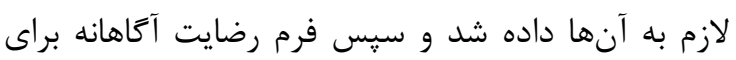

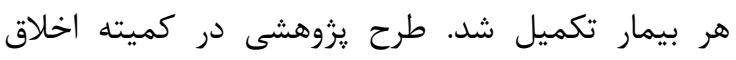

\section{مقدمه}

ضايعات يستان مى تواند انواع مختلفى از ضايعات التهابى تا

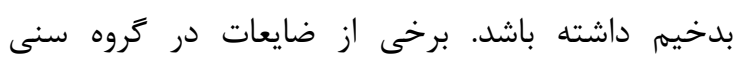

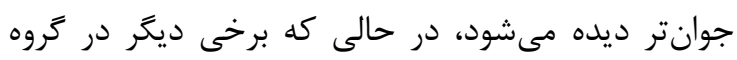

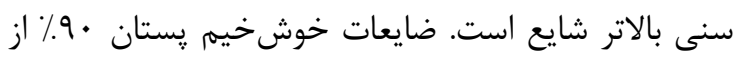
كل ضايعات يستان را تشكيل مىدهد. سرطان پستان

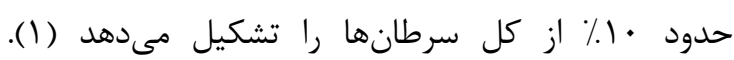

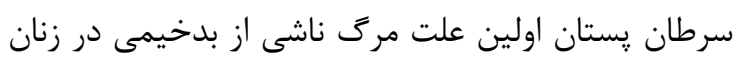
. FF-F.

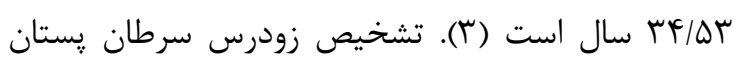

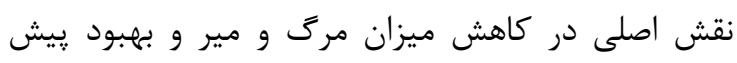

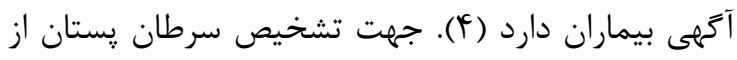
ترياد تشخيصى استفاده مىشود كه شامل معاينه بالينى،

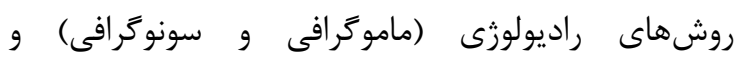
ويزخى هاى سيتولوزى، در تركيب با cell block است كه رونه

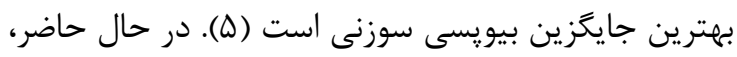

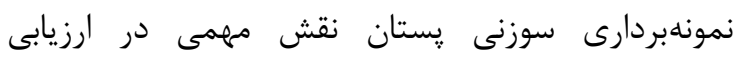

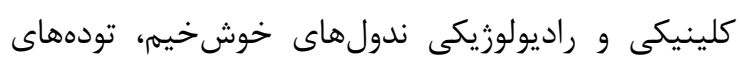

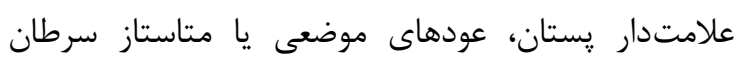

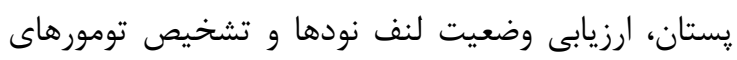

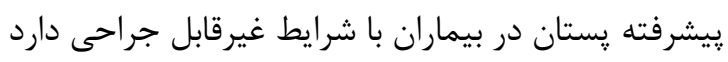

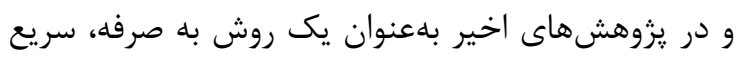

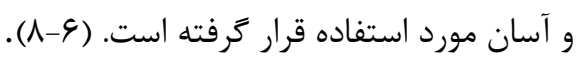

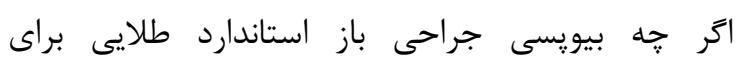

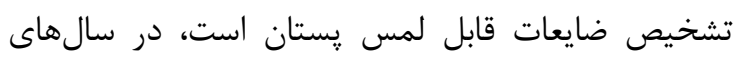

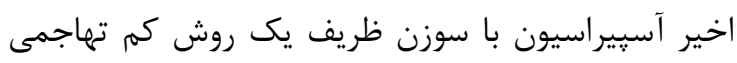
است كه براى تشخيص بدخيمىها مورد استفاده قرار مى كيرد و بهعنوان يك روش تشخيص برخيص بدخى ساده، ايمن،

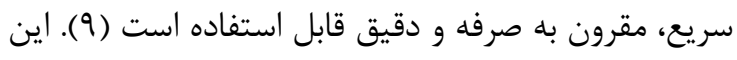
روش اكرجه در تشخيص مفيد هستند اما با اين حال داراى مشكلاتى است كه شامل فيكس شدن غير يكنواخت

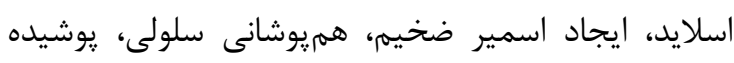

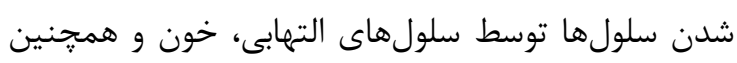

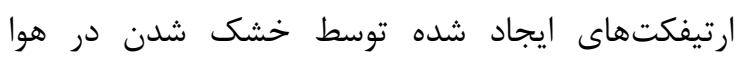

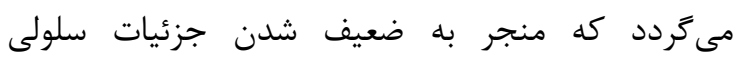

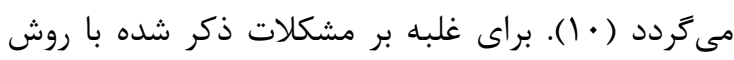

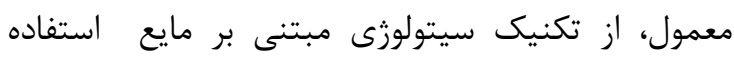

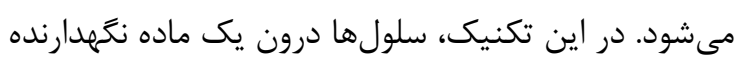
مايع وارد مىشوند و روش يردازش بهصورت استاندارد و 
گززارش شد و از مطالعه حذف شدند و تجزيه و تحليل روى

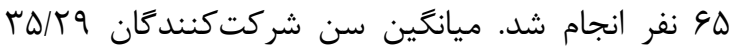

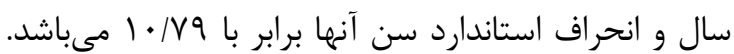

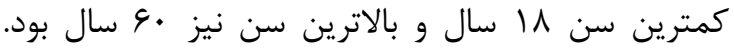

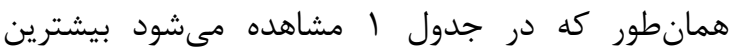

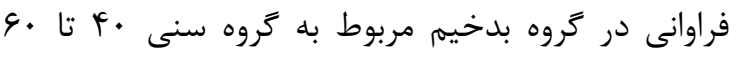

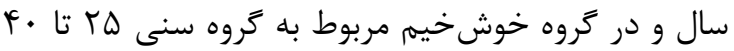

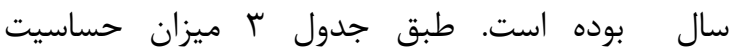

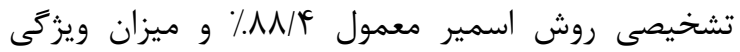

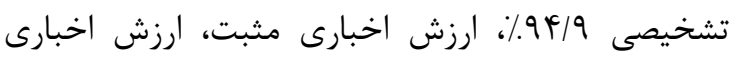

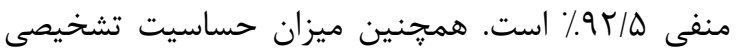

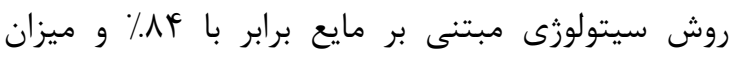

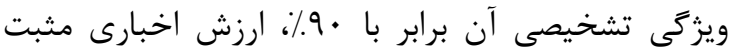

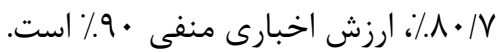
موارد غيرمنطبق (مثبت كاذب و منفى منفى كاذب): سه إن

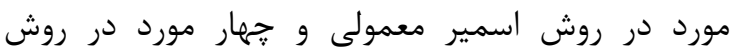

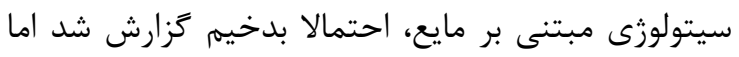

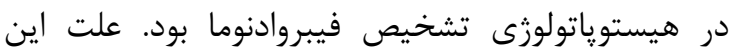

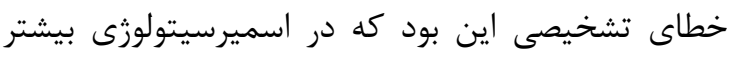
كلاسترهاى سلولى خصوصيات خوش اين بلى ديمى داشتند ولى الى تعدادى كلاسترهاى سلولى كوجى مشاهده شد كه آتيبى آتيى خفيف داشتند و ما آن را در طبقه احتمالا بدخيم كزارش كار كاري كرديم. دو مورد در روش اسمير معمولى، جهار مورد در

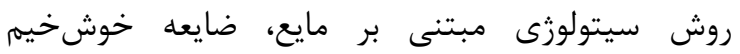

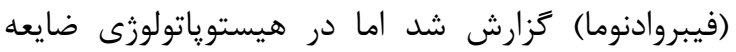
بدخيم بود (كارسينوم مهاجم داكتال درجه يايين). علت

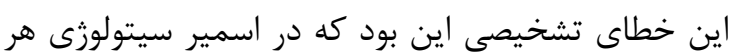

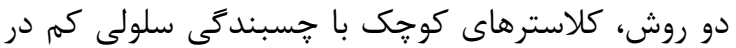

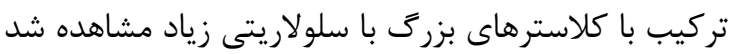

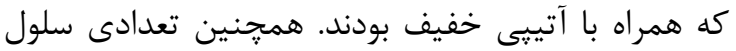

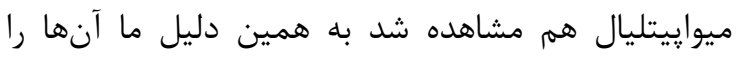

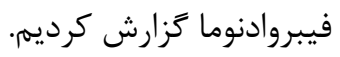

دانشعاه علوم يزشكى بندرعباس با كد

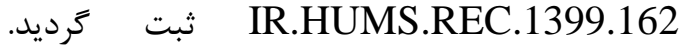
نمونهبردارى سوزنى از توده قابل لمس يستان در شرايط

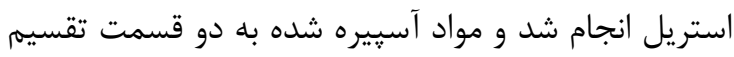
شدند: يك قسمت در محيط مايع نكَه دارنده ساخت كشور

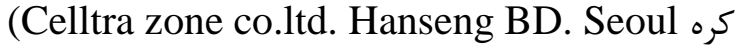
137-863, Korea) سيتوسانتريفيوز شركت "دانش بنيان نوين تشخيص"

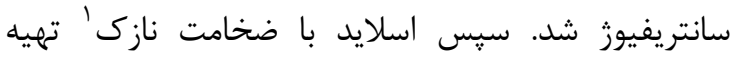

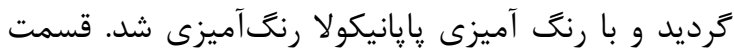
دوم نمونهبردارى سوزنى را روى جهار إسار اسلايد شيشهاى

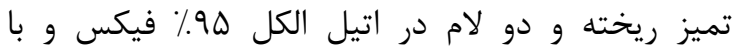

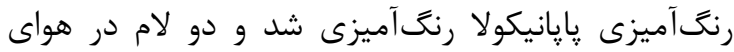

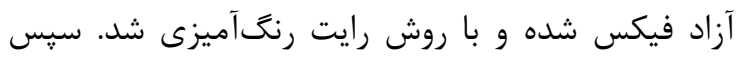

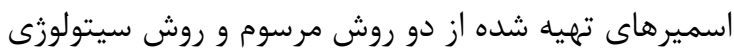

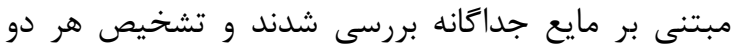

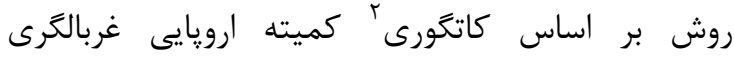

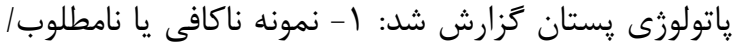

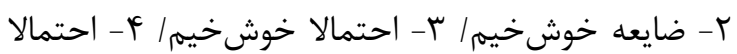
بدخيم/ ه- ضايعه بدخيم. در نهايت، تشخيص نهايى هر

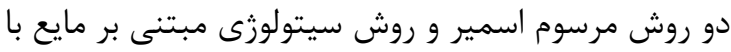

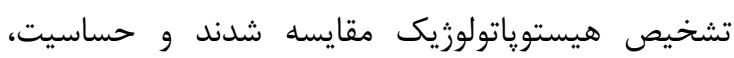

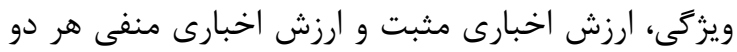

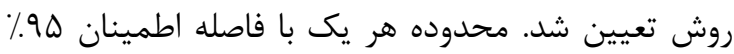

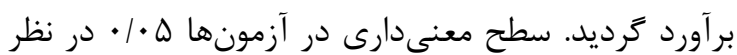

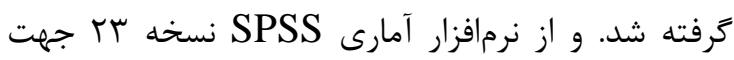
تحليل دادهها استفاده كرديد.

كافتهها

در يك مطالعه توصيفى از \&V بيمار مراجعهكننده به

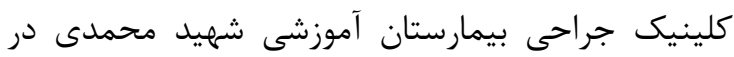

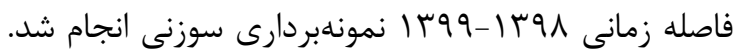
دو نمونه به دليل كاهش سلولاريتى بهعنوان نمونه ناكافى إنى

جدول ا: فراوانى آزمودنى ها به تفكيك ضايعات خوش خيم / بدخيم در كروههاى سنى مختلف هيست ياتولى

\begin{tabular}{|c|c|c|c|c|c|}
\hline \multicolumn{4}{|c|}{ هيستوياتولوزى } & \multirow{4}{*}{ بدخيم } & \multirow{4}{*}{$\begin{array}{r}\text { كروه سنى } \\
\text { (سال }\end{array}$} \\
\hline & & خوش خيم & & & \\
\hline \multirow{2}{*}{ كل } & \multirow{2}{*}{ آبسه } & \multirow{2}{*}{ فيبروادنوما } & سيستيك نوتروفيليك & & \\
\hline & & & كرانولوماتوس ماستيتيس & & \\
\hline $1 \cdot$ & · & $\Lambda$ & $r$ & . & $\Lambda \Lambda-r \Delta$ \\
\hline rq & f & 9 & $\checkmark$ & 9 & $r \Delta-r$. \\
\hline rq & r & r & 4 & 19 & $p \cdot-q$. \\
\hline $9 \Delta$ & $9(9 / \pi)$ & $19(\% 9 / \%)$ & $10(Y K / I)$ & $r \Delta(r N / \Delta)$ & كل \\
\hline
\end{tabular}


جدول r: فراوانى ضايعات خوشخيم و بدخيم در دو روش اسمير معمولى و روش سيتولوزى مبتنى بر مايع

\begin{tabular}{|c|c|c|c|c|c|}
\hline \multirow{2}{*}{ كل } & \multicolumn{2}{|c|}{ سيتولوزى مبتنى بر مايع } & \multicolumn{2}{|c|}{ اسمير معمولى } & \multirow{2}{*}{ 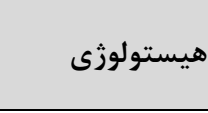 } \\
\hline & منفى & مثبت & منفى & مثبت & \\
\hline ra & r & YI & $r$ & r & بيمار (بدخيم) \\
\hline f. & re & f & rV & r & سالم (خوش خيم) \\
\hline
\end{tabular}

جدول بّ: ميزان حساسيت، ويزَكى، ارزش اخبارى مثبت و ارزش اخبارى منفى روش اسمير معمولى و مبتنى بر مايع

\begin{tabular}{|c|c|c|c|c|}
\hline \multicolumn{2}{|c|}{ فاصله اطمينان ه9٪٪ } & \multicolumn{2}{|c|}{ ميزان بر آورد شده } & \multirow{3}{*}{ شاخص } \\
\hline روش مبتنى بر مايع & روش اسمير معمولى & روش مبتنى & روش اسمير & \\
\hline كران يايين -كران بالا & كران يايين -كران بالا & بر مايع & معمولى & \\
\hline$\Lambda \cdot-19$ & $14-9 r$ & $\Delta F$ & $\Lambda N / \uparrow$ & حساسيت \\
\hline$\wedge 9-9 \Delta$ & $9 \cdot-99$ & 9 . & $94 / 9$ & ويزگى \\
\hline 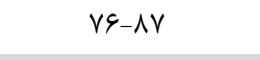 & $1 \Lambda-9 \Delta$ & $\Lambda \cdot / V$ & $q r$ & ارزش اخبارى مثبت \\
\hline$\wedge V-9 F$ & $\wedge \vee-१ ९$ & 9. & $9 r / 0$ & ارزش اخبارى منفى \\
\hline
\end{tabular}

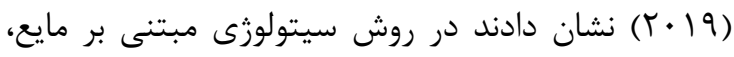

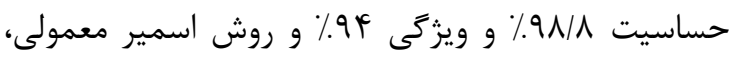

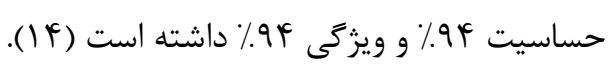

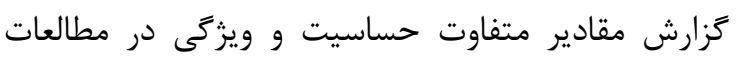

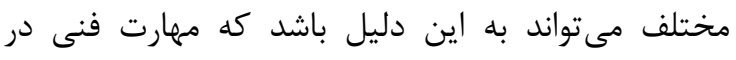

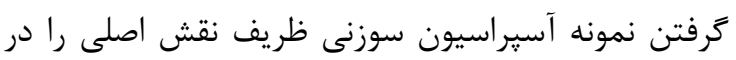

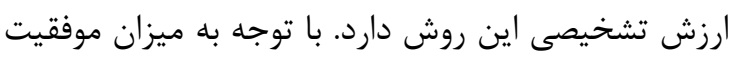

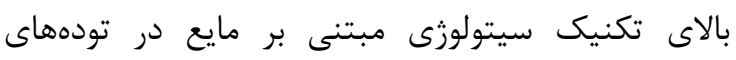

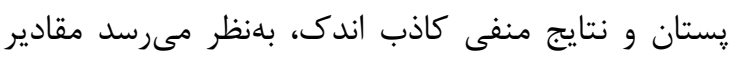

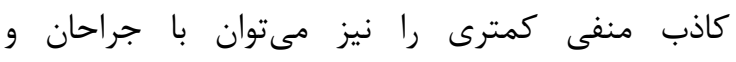

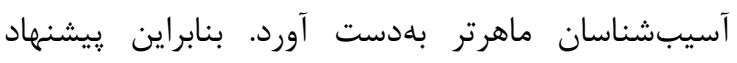
مىشود براى افزايش حساسيت و ويزگىى، از فرد ماهر و و با بانيا تجربه جهت گرفتن نمونه آسيّراسيون سوزنى استفاده

موارد غيرمنطبق (مثبت كاذب و منفى كاذب): در

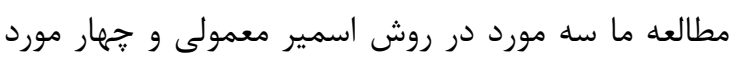

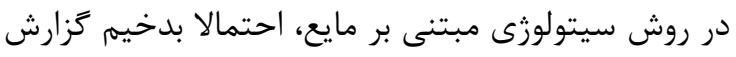

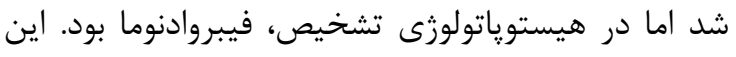
يافتها همسو با مطالعات ديكر محققان بود. آنها بيان

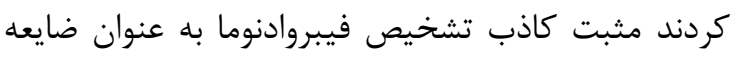
احتمالا بدخيم در روش سيتولوزى مبتنى برديت بر مايع بيشتر از

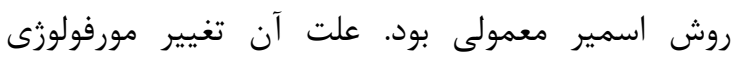

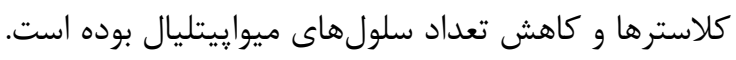

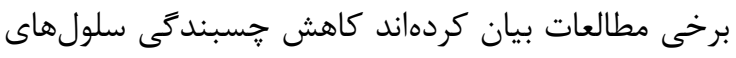
كلاستر و ايجاد كلاسترهاى سست همجنين هستكهاى

هدف از مطالعه حاضر، بررسى حساسيت و ويزگى

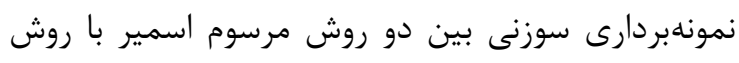

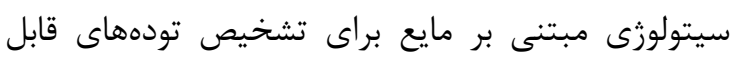

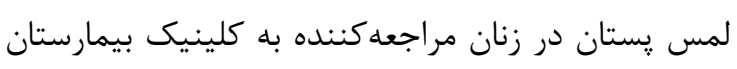

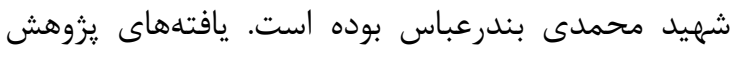

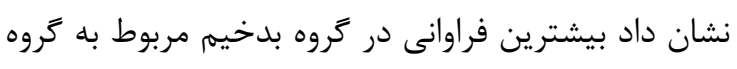

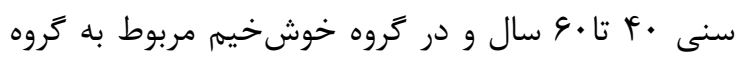

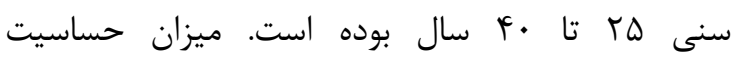

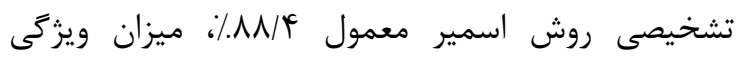

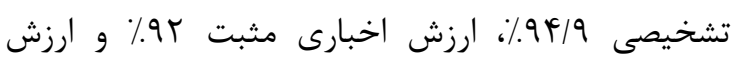

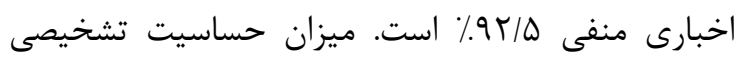

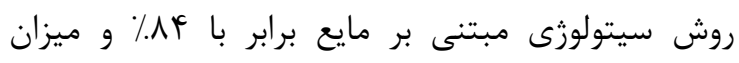

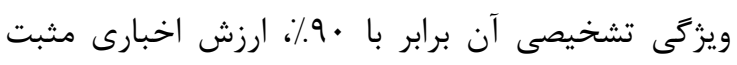

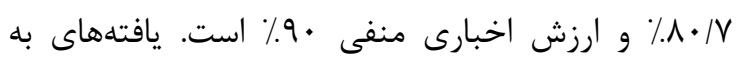

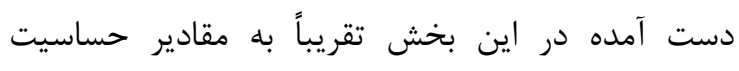

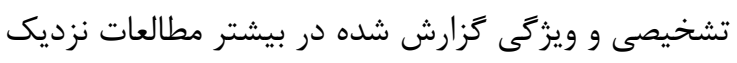

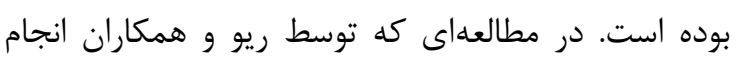

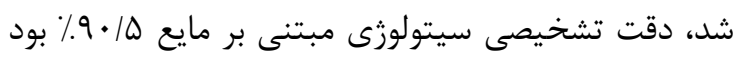

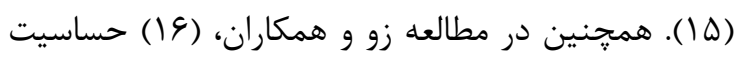

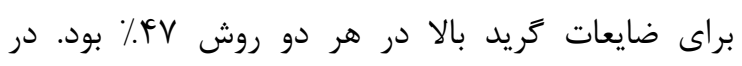

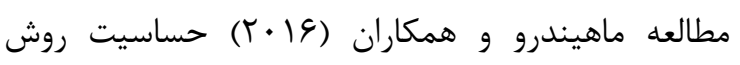

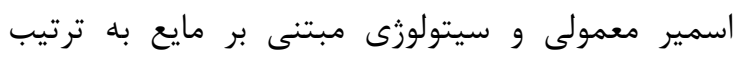

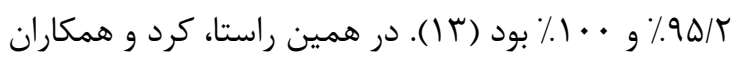


(آزمايش سهكانه)، قطعاً حساستر خواهد بود. از آنجا كه موفقيت بررسى اسميرسيتولوزى مبتنى بر مايع به تجربه آسيبشناس بستكى دارد پيشنهاد مى گردد براى تفسير بهتر نمونه، از متخصص سيتوياتولوزى با تجربه و وآشنا به به ديه تفاوتهاى سيتولوزى بين دو روش (سيتولوزى مبتنى بر برن مايع و روش معمولى)، استفاده كردد.

\section{نتيجهكيرى}

روش سيتولوزى مبتنى بر مايع در مقايسه با روش مرسوم

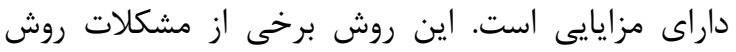

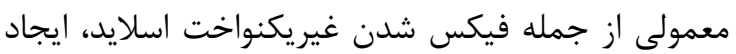
اسمير ضخيم، هميوشانى سلولى، يوشيده شدن سلولها توسط سلول هاى التهابى و خون، و همجنين ارتيفكتهاى ايجاد شده توسط خشك شدن در هوا كه منجر به ضعيف

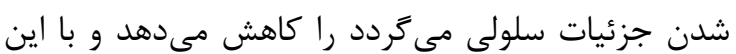

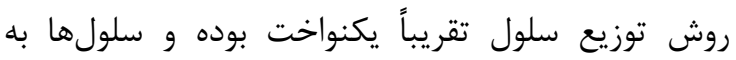

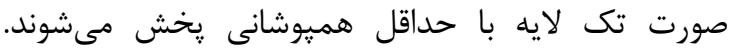

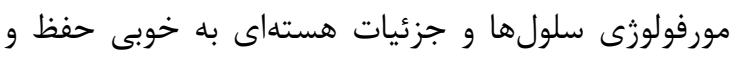
تقويت مى

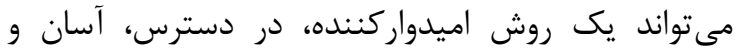

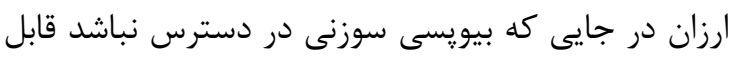

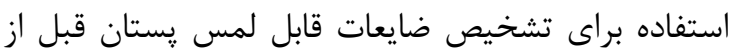
عمل جراحى باشد.

\section{تشكر و قدردانى}

اين مقاله بركرفته از پاياننامه دكتراى (تخصصى) در رشته

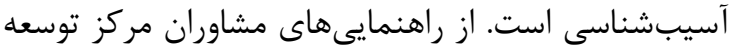

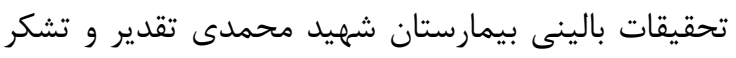

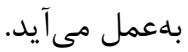

\section{تعارض منافع}

نويسندكان اين مقاله هيجَّونه تعارض منافعى در خصوص مالكيت دادهاى مورد استفاده و نتايج ارايه شده ندارند.

\section{References}

1. Pawar PS, Gadkari RU, Swami SY, Joshi AR. Comparative study of manual liquid-based cytology (MLBC) technique and direct smear
برجسته، باعث خطاى تشخيصى فيبروادنوما در اسمير سيتولوزى مى گردد. برخى از كارسينوماى داكتال درجه يايين نيز ممكن است منجر به تشخيص منفى كاذب شوند زيرا در روش سيتولوزى مبتنى بر مايع سلولها كوجى هستند و آتييى هستهاى خفيفتر است، اما غربالكرى رئى دقيق اسلايدها تغييرات سيتولوزيكى به نفع بدخيمى را نشان مىدهد از جمله وجود سلولهاى تكى إيتليالى و

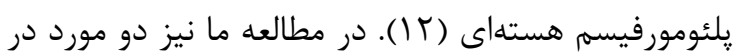
روش اسمير معمولى و جهار مورد در روش سيتولوزى مبتنى بر مايع، ضايعه خوشخيم (فيبروادنوما) تَزارش شد

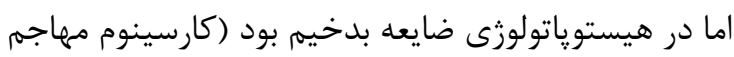
داكتال درجه يايين). روش سيتولوزى مبتنى بر مايع به دليل تكنيك يردازش

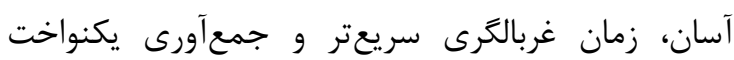
نمونه، حفظ شكل سلول و جزئيات هسته و زمينه تميز لام به دليل حذف سلولهاى خونى نسبت به روش اسمير

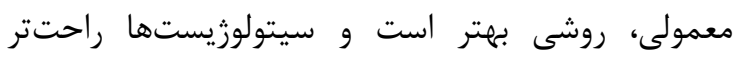

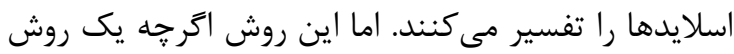
در دسترس، آسان و ارزان است با اين حال، كاهى اوقات عملكرد آن براى تشخيص دقيق كافى نيست و خطان

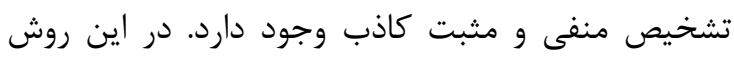
محدوديتهايى وجود دارد، برخى از آنها شامل عدم تمايز بين ضايعات خوش خيم و بدخيم است كه ممكن است كاهى به دليل از دست دادن قابل توجه سلول در هنغام

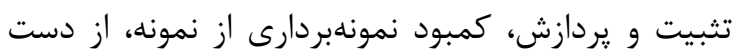
دادن ساختار بافت شناسى، شباهت سلولهاى خوشخيم به بدخيمى توسط سلولهاى دزنراتيو يا شرايط التهاب شديد كه منجر به تشخيص منفى كاذب و مثبت كاذب مىشود. يكى از دلايل مهم نتايج منفى كاذب آسيراسيون سوزنى

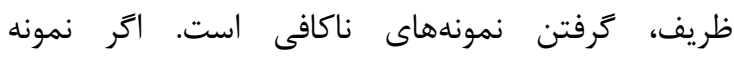
آسيراسيون توسط يك يزشك با تجربه گرفته شود و لام

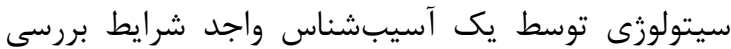
شود و در كنار آن ماموگر افى و سونوگرافى هم انجام شود

technique (conventional) on fine-needle cytology/fine-needle aspiration cytology 
samples. Journal of Cytology/Indian Academy of Cytologists. 2014; 31(2): 83.

2. Ban KA, Godellas CV. Epidemiology of breast cancer. Surg Oncol Clin N Am. 2014; 23(3): 409-22.

3. Roshandel G, Ghanbari-Motlagh A, Partovipour E, Salavati F, Hasanpour-Heidari S, Mohammadi G, et al. Cancer incidence in Iran in 2014: results of the Iranian National Population-based Cancer Registry. Cancer epidemiology. 2019; 61:50-8.

4. Berner A, Sauer T. Fine-needle Aspiration Cytology of the Breast. Ultrastructural Pathology. 2011; 35(4):162-7.

5. Mohanty P, Sahoo N, Das D. Malignant melanoma: A double malignancy or second malignant neoplasm in a patient of acute lymphoblastic leukemia following therapy with a composite karyotype. International Journal of Applied and Basic Medical Research. 2020; 10(3): 218.

6. Kocjan G, Bourgain C, Fassina A, Hagmar B, Herbert A, Kapila K, et al. The role of breast FNAC in diagnosis and clinical management: a survey of current practice. Cytopathology. 2008; 19(5): 271-8.

7. Sharif A, Tabassum T, Riaz M, Akram M, Munir N. Cytomorphological patterns of palpable breast lesions diagnosed on fine needle aspiration cytology in females. European Journal of Inflammation. 2020; 18:1-8.

8. Moazeni Bistgani M, Basravi M, Taheri A, Taheri S, Kheiri S. Accuracy of fine needle aspiration compared to core needle biopsy in breast masses. Journal of Shahrekord University of Medical Sciences. 2019; 21(2): 75-9.

9. Osiagwu D, Awolola N, Bankole J, Otegbade M, Oyegbami R, Awopetu P. Comparison of Diagnostic Fine-Needle Aspiration of Breast Masses Obtained from Cell Blocks and
Conventional Smear Methods Using Prognostic/Predictive Biomarkers for Confirmation. J Med Lab Sci. 2020; 30(3): 3549.

10. Nassar A. Core needle biopsy versus fine needle aspiration biopsy in breast-a historical perspective and opportunities in the modern era. Diagnostic cytopathology. 2011; 39(5): 380-8.

11. Simsir A, Cangiarella J. Challenging breast lesions: Pitfalls and limitations of fine-needle aspiration and the role of core biopsy in specific lesions. Diagnostic cytopathology. 2012; 40(3): 262-72.

12. Gerhard R, Schmitt FC. Liquid-based cytology in fine-needle aspiration of breast lesions: a review. Acta cytologica. 2014; 58(6): 533-42.

13. Mahinderu K, Nandini N, Kishore A, Singh AK. manual liquid based cytology in breast fine needle aspiration-comparison with the conventional smear. IOSR J Dent Med Sci. 2016; 1: 17-24.

14. Kord S, Mokhtari M, Tahmasebi S. Comparison of liquid-based and conventional cytology in diagnosis of breast mass. Journal of cytology. 2019; 36(1): 22.

15. Ryu HS, Park IA, Park SY, Jung YY, Park $\mathrm{SH}$, Shin H-C. A pilot study evaluating liquidbased fine needle aspiration cytology of breast lesions: a cytomorphological comparison of SurePath liquid-based preparations and conventional smears. Acta cytologica. 2013; 57(4): 391-9.

16.Zhu J, Norman I, Elfgren K, Gaberi V, Hagmar B, Hjerpe A, et al. A comparison of liquid-based cytology and Pap smear as a screening method for cervical cancer. Oncology reports. 2007; 18(1): 157-60. 